\title{
AVALIAÇÃO DO USO DO EXTRATO BRUTO DE Jatropha gossypiifolia L. NA CICATRIZAÇÃO DE FERIDAS CUTÂNEAS EM RATOS
}

\author{
Evaluation of the use of raw extract of Jatropha gossypiifolia L. in the healing process of \\ skin wounds in rats
}

\begin{abstract}
Manoel Francisco da Silva Santos 2 , Nicolau Gregori Czeczko ${ }^{4}$, Paulo Afonso Nunes Nassif ${ }^{4}$, Jurandir Marcondes Ribas-Filho ${ }^{4}$, Bruno Leonardi Freire de Alencar ${ }^{5}$, Osvaldo Malafaia ${ }^{4}$, Carmen Australia Paredes Marcondes Ribas $^{4}$, Vagner Marcolin Trautwein ${ }^{6}$, Gilberto Simeone Henriques ${ }^{4}$, José Maria Ayres Maia ${ }^{3}$ e Ruy Carlos de Araújo Bittencourt $^{5}$

1. Trabalho realizado no laboratório de pesquisas do Centro de Ciências Biológicas e da Saúde da Universidade Federal do Maranhão

2. Professor do Departamento de Cirurgia da Universidade Federal do Maranhão

3. Médico do Hospital da Universidade Federal do Maranhão

4. Professor Doutor em Cirurgia

5. Aluno de Pós-Graduação - Mestrado

6. Aluno de Pós-Graduação - Doutorado
\end{abstract}

\section{RESUMO}

Introdução: O uso de fitoterápicos na cicatrização de feridas cirúrgicas tem sido incrementado nos últimos anos com a busca de princípios ativos que desempenhe efetivo papel neste processo acelerando a recuperação cirúrgica. Objetivo: Avaliar os aspectos morfológicos do processo cicatricial de feridas cutâneas abertas de ratos com uso do extrato bruto de Jatropha gossypiifolia L. Métodos: Utilizaram-se 60 ratos da linhagem Wistar. Em cada animal foi realizada uma ferida de $2 \mathrm{~cm}$ de diâmetro na região dorsal. Os animais foram distribuídos em dois grupos de 30: grupo Controle - sem tratamento e grupo Jatropha - aplicação de extrato bruto de Jatropha gossypiifolia L. Cada grupo foi subdividido em três subgrupos de 10 animais e avaliados no $7^{\circ}, 14^{\circ}$ e $21^{\circ}$ dias do pós-operatório. Realizou-se estudo comparativo entre os dois grupos através da análise macroscópica, a planigrafia digital e análise histológica tendo como parâmetro a proliferação vascular, polimorfonucleares, mononucleares, proliferação fibroblástica, colagenização e reepitelização. Resultados: Na evolução da ferida cutânea tanto no grupo controle como no grupo Jatropha houve exsudação plasmática com formação de crostas superficiais até o $7^{\circ}$ dia. A partir dai houve espessamento da crosta e no $14^{\circ}$ dia a crosta se destacou, evoluindo para tecido de granulação e epitelização completa no $21^{\circ}$ dia com surgimento de novos pelos ao redor da lesão, em todos os animais. Houve ausência significativa da inflamação aguda no $21^{\circ}$ dia pós-operatório do grupo Jatropha. Houve diferença significativa na intensidade da inflamação crônica, sendo mais intensa no $7^{\circ}$ dia no grupo controle. A proliferação fibroblástica foi mais acentuada no $7^{\circ}$ dia pós-operatório do grupo Jatropha, sendo semelhante no $14^{\circ}$ e $21^{\circ}$ dias pós-operatórios nos demais. A colagenização foi maior no $7^{\circ}$ e $14^{\circ}$ dias no grupo Jatropha. A re-epitelização foi significativamente melhor no $7^{\circ}$ dia do grupo Jatropha. Conclusão: Embora mostrando melhora histológica com o uso da Jatropha, não ocorreu diferença significativa entre os grupos nas variáveis analisadas, na cicatrização das feridas cutânea de ratos ao término da avaliação.

Descritores: Fitoterapia. Cicatrização de Feridas. Ratos. Jatropha.

\begin{abstract}
Introduction: Phytotherapy is one of the research branches in the healing process of surgical wounds. Purpose: To analyze the morphological aspects of the healing process occurring in open skin lesions in rats under administration of raw extract from Jatropha Gossypiifolia L. Method: Sixty Wistar rats were utilized. A $2 \mathrm{~cm}$ wound in diameter was done in each animal at the dorsal region. The animals were divided into two groups, each one consisting of 30 animals. Each group was subdivided into three subgroups of ten. They were analyzed in the $7^{\text {th }}, 14^{\text {th }}$ and $21^{\text {st }}$ post-operative day. The two groups were compared through macroscopic analysis using digital planigraphy and histological examination. The microscopic parameters considered were the vascular proliferation, polymorph and mononuclear cells, fibroblastic proliferation, collagen and epithelium formation. Results: Epitelization occurred in a same amount in all animals. There was no chronic inflamation on $21^{\text {st }}$ day in the Jatropha group and also no difference in polimorphonuclear cells between the groups. The fibroblastic reaction was better on the $7^{\text {th }}$ day in the Jatropha group and equal in the remaining ones. Colagenization was greater on $7^{\text {th }}$ and $14^{\text {th }}$ days in Jatropha and better re-epitelization occurred in the same group in the $7^{\text {th }}$ day. Conclusion: Although with hystologic aspects favoring the Jatropha, no significant differences concerning to the macroscopic and microscopic aspects were observed among the skin wounds receiving raw extract Jatropha and those that received no treatment in the final evaluation.
\end{abstract}

Key Words: Phythotherapy. Wound Healing. Rats. Jatropha. 


\section{Introdução}

O histórico da descoberta e utilização de fármacos originários de plantas data de vários séculos, já sendo descrito por Shen-Nung (2838-2698 a.C.), importante monarca e considerado o pai da tradicional medicina chinesa. Utilizava curativos de plantas e escreveu o Pen Tsan (O Herbário), um tratado onde menciona o uso de plantas como: papola cânhamo, cinamomo e mandrágora. Pedamaos Dioscórides (40 a 90 a.D.), médico grego, natural de Anazarba na Cílicia, escreveu um livro chamado Matéria Médica. Onde relatou o uso de mais de 600 plantas, muitas que já não mais existem ${ }^{1}$.

A utilização de substâncias tópicas, para melhorar o processo de cicatrização tem sido largamente estudado ${ }^{2,3,4,5,6,7,8}$. Os antigos babilônicos, egípcios e tantos outros povos no passado, faziam uso de minerais e plantas medicinais. No papiro de Edwin Smith encontram-se descritos tratamentos dos feridos de guerra com a aplicação de uma combinação de mel e ungüentos sobre as feridas ${ }^{1}$.

São muitos os fatores que vem colaborando no desenvolvimento de práticas de saúde que incluíam plantas medicinais, principalmente econômicos e sociais, inclusive recebendo incentivo da própria Organização Mundial de Saúde. Entretanto, ainda hoje persiste um certo ar de mistério quando utilizam-se estas plantas, principalmente em virtude das suas relações com a mitologia e o desconhecimento da fração ativa no efeito desejado.

No Estado do Maranhão, que faz parte da Hiléia Amazônica, existe a espécie Jatropha gossypiifolia L. pertencente à família Euphorbiaceaes, uma das maiores dicotiledôneas da região ${ }^{9,10}$. Esta família compreende 290 gêneros e aproximadamente 7.500 espécies, distribuídos em todo o mundo, principalmente nas regiões tropicais. A espécie local é denominada popularmente de diversas formas, mas mais comumente de pião roxo. Possui folhas e frutos com propriedades medicinais, com grande uso na medicina popular como; agente anti-inflamatório de aplicação local contra inflamação dos olhos, anti-hipertensivo e anti-reumatico, entre outras ${ }^{11,12}$. O uso local do seu látex é tido como útil contra feridas e mordidas de animais peçonhentos, no Piauí $^{13}$. Em Brasília, as sementes são usadas contra gripes fortes ${ }^{14}$; no Pará, o chá das folhas é usado como antitérmico e o banho contra feridas ${ }^{15}$.

Não encontrou-se na literatura consultada, nenhum trabalho experimental do uso tópico do extrato bruto da espécie Jatropha gossypiifolia L. na cicatrização de lesões de pele. Deste modo, objetivou-se um estudo em animal de experimentação, para avaliar o seu uso na cicatrização de feridas cutâneas em ratos, com análise macroscópica, planigrafia digital e análise histológica.

\section{Métodos}

Este estudo foi aprovado pelo Comitê de Ética em Pesquisa da Universidade Federal do Maranhão - UFMA em São Luiz - MA.

Foram utilizados 60 ratos (Rattus Norvegicus albinus) da linhagem Wistar, machos, com peso variando entre 140 e 200g no início do experimento, procedente do Biotério Central da Universidade de Campinas - São Paulo.

Os ratos foram divididos em dois grupos de 30 animais, conforme o uso ou não do fitoterápico. Os grupos foram denominados: grupo controle e grupo Jatropha e avaliados no $7^{\mathrm{a}}, 14^{\mathrm{o}}$ e $21^{\circ}$ dias do pós-operatório.

Após a anestesia, cada rato era posicionado em decúbito ventral, imobilizado em prancha operatória e submetido a epilação na região dorsal em área de $6 \mathrm{~cm}^{2}$.

Para a demarcação da pele a ser retirada, utilizou-se um punch metálico com lâmina cortante na sua borda inferior. Seguia-se a retirada de um fragmento cutâneo com $2 \mathrm{~cm}$ de diâmetro no centro da área epilada, até a exposição da fáscia muscular dorsal.

Após a hemostasia, por compressão local, nos animais do grupo controle não utilizou-se aplicação de medicamentos ou curativo. No grupo Jatropha realizou-se, gotejamento com seringa de insulina de $0,1 \mathrm{ml}$ do extrato bruto de Jatropha, após o procedimento operatório, continuando a aplicação nos dias subseqüentes uma vez por dia na concentração de 100 mg/ml, pela manhã e sem curativo.

Cada grupo animal foi dividido em três sub-grupos, que eram mortos por dose letal de éter por via inalatória, no $7^{\circ}, 14^{\circ}$ e $21^{\circ}$ dias do pós-operatório. Os ratos foram numerados de 1 a 60 .

\section{Avaliação macroscópica}

Para determinação do maior diâmetro da ferida e os seus aspectos macroscópicos utilizou-se uma lupa com 2,5 vezes de aumento. A ferida foi medida no maior diâmetro com paquímetro digital, graduado em milímetros. Os dados foram anotados em ficha protocolo para posterior comparação. As medidas foram realizadas no $7^{\circ}, 14^{\circ}$ e $21^{\circ}$ dias de observação.

Depois de sacrificados, os animais foram fotografados com máquina fotográfica digital, fixada em tripé, mantida a uma distância constante de $34 \mathrm{~cm}$ da área cirúrgica. As imagens foram transferidas para um computador Pentium IV e analisadas através do Software Auto Cad 14 (Autodesk, Estados Unidos), com seu aplicativo Poliline para cálculo da área da ferida cutânea, tendo como referência a medida do maior diâmetro realizada com o paquímetro digital e transformada em medida decimal (Figura 1).

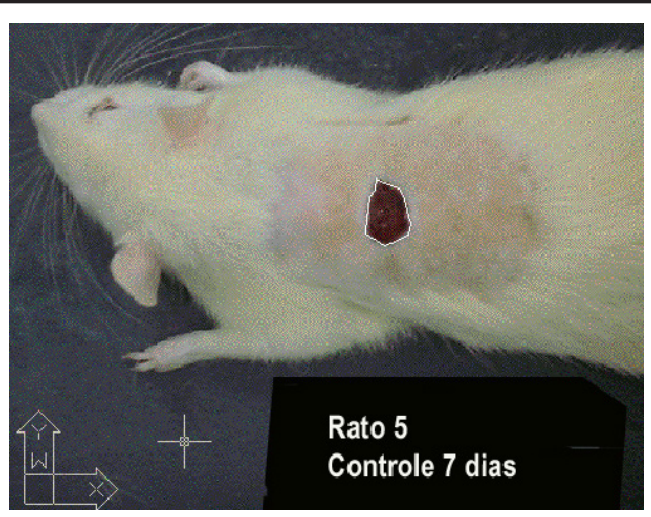

FIGURA 1 - Aspecto da área cirúrgica no dorso do animal digitalizada para análise no software Auto Cad 14 


\section{Processamento histológico}

O processamento histológico e a análise das lâminas foram realizados no Laboratório de Patologia do Hospital Universitário Presidente Dutra - UFMA.

A peça cirúrgica foi retirada logo após a morte do animal, sendo constituída da cicatriz ou lesão cutânea, com margem de $1 \mathrm{~cm}$ de pele em torno da lesão, com profundidade até a musculatura dorsal do animal, sendo identificada cada peça isoladamente. A partir do material fixado em formol a $10 \%$, procedeu-se à técnica histológica de rotina incluindo as etapas de desidratação gradativas, diafanização, infiltração e emblocamento em parafinas das amostras. A partir de cada bloco de parafina obteve-se lâminas de cada animal posteriormente corada pela técnica de Hematoxilina-Eosina e Tricômico de Masson. As lâminas foram numeradas de acordo com o número do animal e subgrupo a que pertencia.

\section{Avaliação microscópica}

As análises dos cortes histológicas foram realizadas em
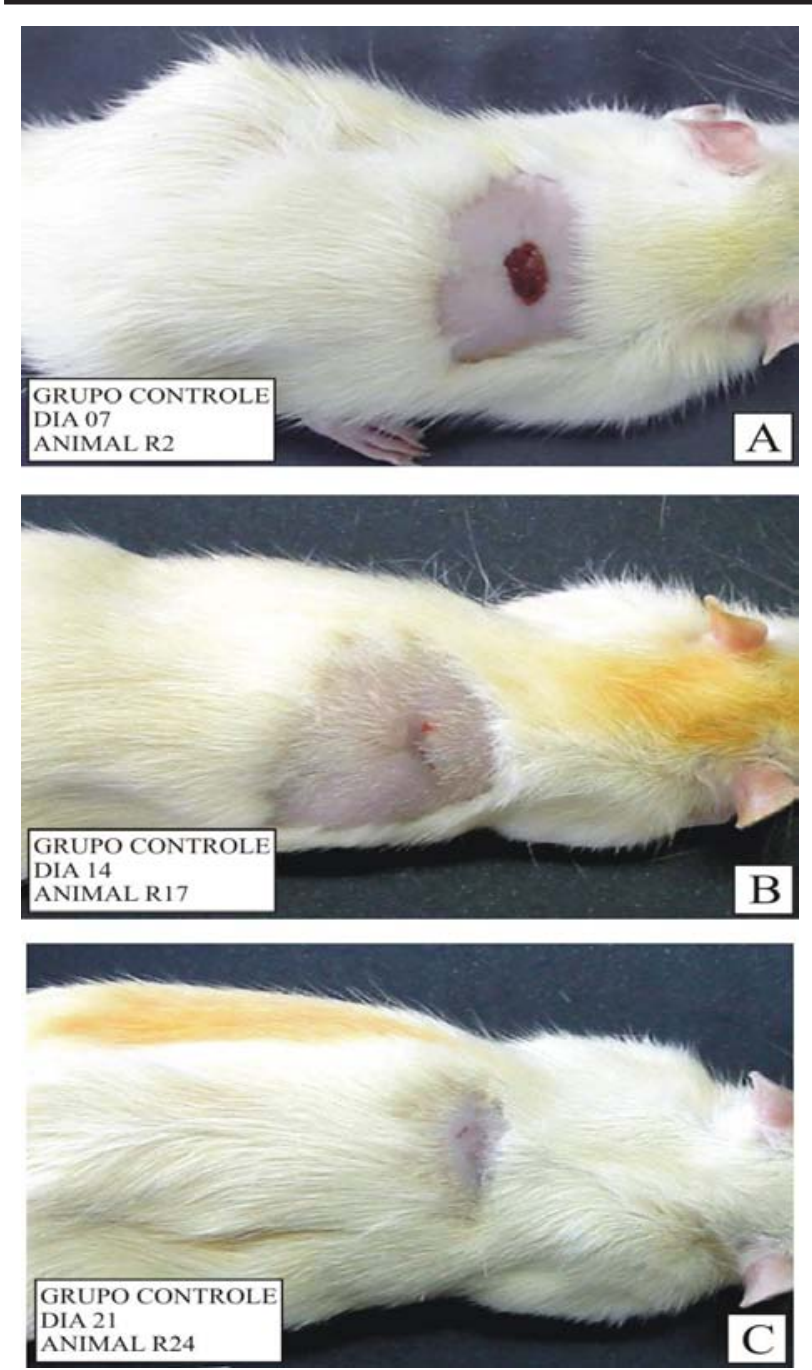

FIGURA 2 - Fotos de animais do grupo controle mostrando as lesões cutâneas no $7^{\circ}(\mathrm{A}), 14^{\circ}(\mathrm{B}), 21^{\circ}(\mathrm{C})$ dias do pós-operatório microscópico tetraocular pelo mesmo patologista e um dos autores (MFSS). O campo histológico de cada lâmina da ferida cutânea foi avaliado, utilizando-se as objetivas de 5, 10 e 40 vezes de aumento e ocular de 10 vezes. Os critérios histológicos incluíram: inflamação aguda, inflamação crônica inespecífica, proliferação fibroblástica, colagenização e epitelização da ferida.

Os dados foram analisados utilizando-se o programa Statistica for Windows 5.1 (MICROSOFT), os testes t de Student, Mann-Whitney e Kruskal-Wallis.

\section{Resultados}

Na evolução da ferida cutânea tanto no grupo controle como no grupo Jatropha houve exsudação plasmática com formação de crostas superficiais até o $7^{\circ}$ dia. A partir daí houve espessamento da crosta. Após o $14^{\circ}$ dia a crosta se destacou, evoluindo para tecido de granulação e epitelização completa no $21^{\circ}$ dia, com surgimento de novos pelos ao redor da lesão em todos os animais (Figuras 2 e 3 ).
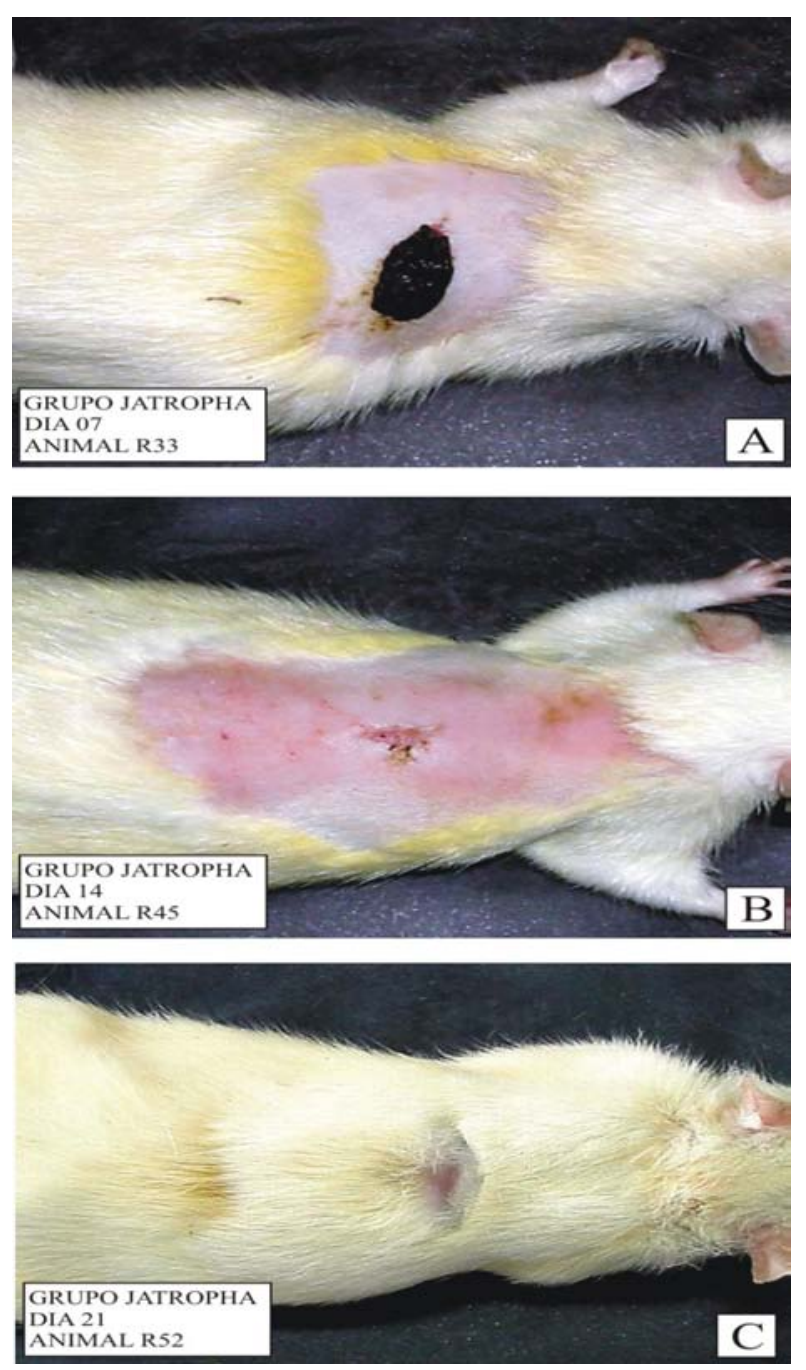

FIGURA 3 - Fotos de animais do grupo Jatropha mostrando as lesões cutâneas no $7^{\circ}(\mathrm{A}), 14^{\circ}(\mathrm{B}), 21^{\circ}(\mathrm{C})$ dias do pós-operatório 
TABELA 1 - Intensidade da inflamação aguda com avaliação da proliferação vascular observadas na fase de reparação tecidual.

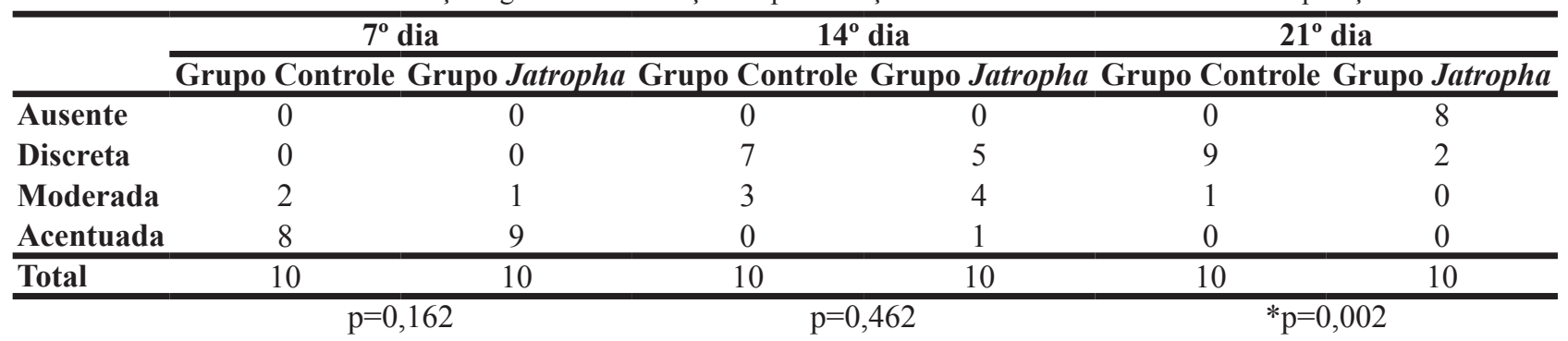

TABELA 2 - Intensidade da inflamação aguda com avaliação de polimorfonucleares observadas na fase de reparação tecidual.

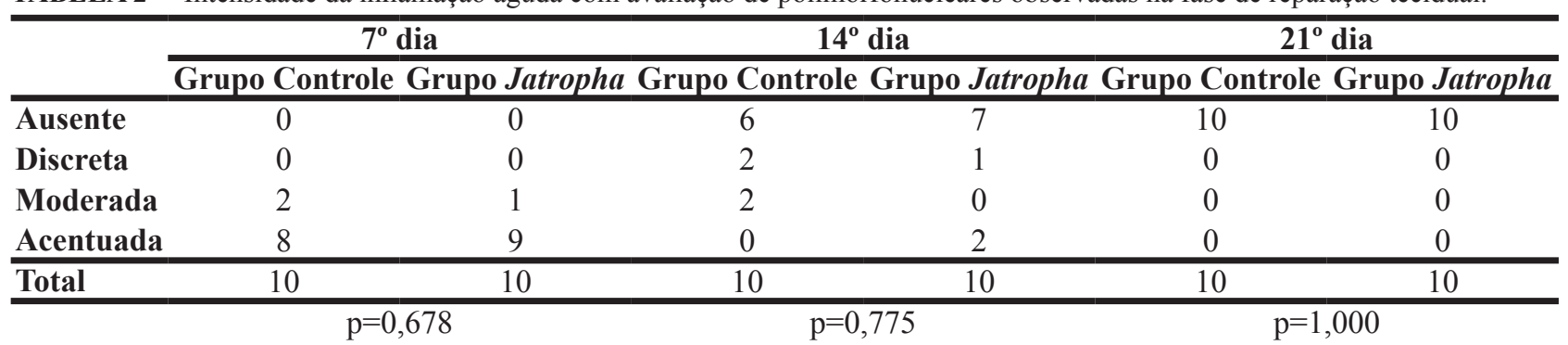

TABELA 3 - Intensidade da inflamação crônica com avaliação dos mononucleares observadas na fase de reparação tecidual.

\begin{tabular}{|c|c|c|c|c|c|c|}
\hline & \multicolumn{2}{|c|}{$7^{0}$ dia } & \multicolumn{2}{|r|}{$14^{\circ}$ dia } & \multicolumn{2}{|c|}{$21^{\circ}$ dia } \\
\hline & Grupo Controle & Grupo Jat & o Cor & role Grupo $\mathrm{Ja}$ & $\mathrm{Co}$ & o Jatropha \\
\hline Ausente & 0 & 0 & 1 & 9 & 0 & 0 \\
\hline Discreta & 0 & 10 & 4 & 1 & 9 & 10 \\
\hline Moderada & 2 & 0 & 5 & 0 & 1 & 0 \\
\hline Acentuada & 8 & 0 & 0 & 0 & 0 & 0 \\
\hline Total & 10 & 10 & 10 & 10 & 10 & 10 \\
\hline
\end{tabular}

TABELA 4 - Intensidade da proliferação fibroblástica na fase de reparação tecidual

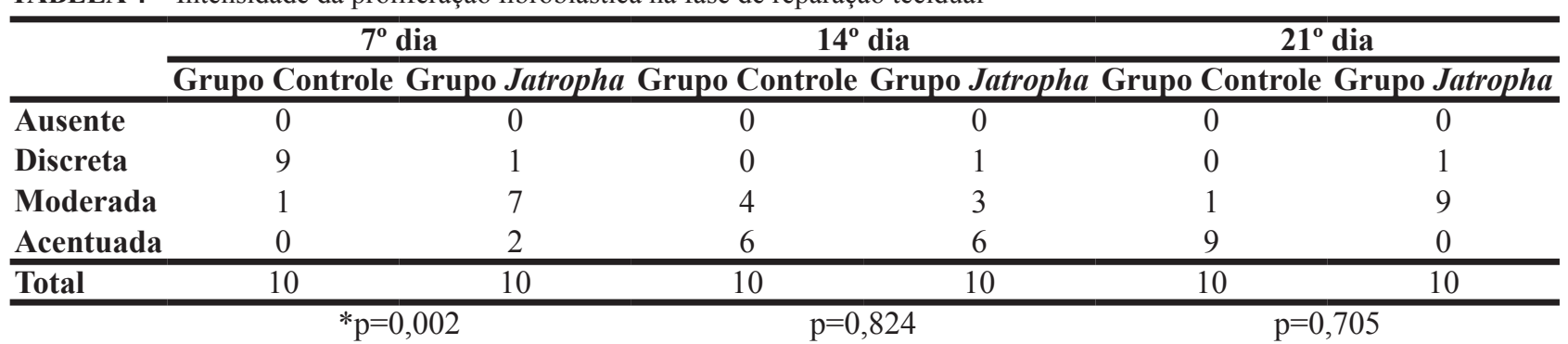

TABELA 5 - Intensidade da colagenização observada na reparação tecidual

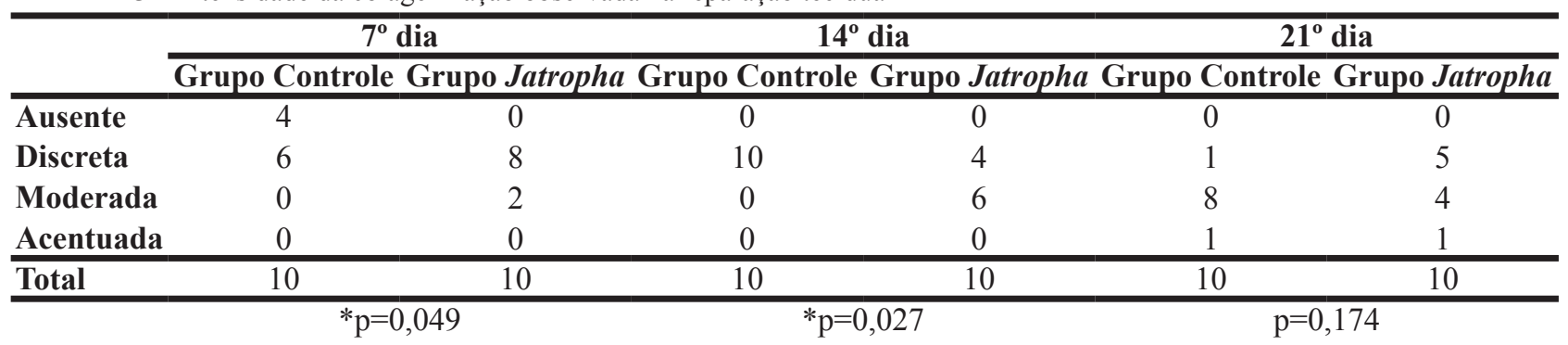

TABELA 6 - Intensidade da reepitelização observada na fase de reparação tecidual.

\begin{tabular}{lcccccc} 
& \multicolumn{2}{c}{$\mathbf{7}^{\mathbf{0}} \mathbf{~ d i a}$} & \multicolumn{1}{c}{$\mathbf{1 4}^{\mathbf{0}}$ dia } & $\mathbf{2 1}^{\mathbf{0}}$ dia \\
\cline { 2 - 7 } & Grupo Controle Grupo Jatropha & Grupo Controle Grupo Jatropha & Grupo Controle Grupo Jatropha \\
\hline Ausente & 10 & 3 & 0 & 1 & 0 & 0 \\
Parcial & 0 & 6 & 2 & 0 & 0 & 0 \\
Completa & 0 & 1 & 8 & 9 & 10 & 10 \\
\hline Total & 10 & 10 & 10 & $\mathrm{p}=1,000$ & $\mathrm{p}=1,000$
\end{tabular}


Os resultados dos vários parâmetros da análise histológica são apresentados comparativamente, conforme o período pós-operatório.

A Tabela 1 resume os resultados da proliferação vascular. Houve ausência significativa da inflamação aguda no $21^{\circ}$ dia pós-operatório do grupo Jatropha.

A Tabela 2 apresenta os resultados da intensidade de polimorfonucleares nas feridas dos animais. Não houve resultado comparativo significativo.

A Tabela 3 discrimina a análise da reação inflamatória crônica ocorrida na cicatrização das feridas dos animais. Houve diferença significativa na intensidade da inflamação crônica, sendo mais intensa no $7^{\circ}$ dia pós-operatório do grupo controle.

A análise da proliferação fibroblástica foi mais acentuada significativamente no $7^{\circ}$ dia do pós-operatório do grupo Jatropha, sendo semelhante no $14^{\circ}$ e $21^{\circ}$ dias do pós-operatórios em todos os animais (Tabela 4).

$\mathrm{Na}$ análise histológica da colagenização houve resultado significativo no $7^{\circ}$ e $14^{\circ}$ dias do pós-operatório, com acentuação do processo no grupo Jatropha (Tabela 5 e 6).

\section{Discussão}

Rotineiramente utiliza-se o rato como modelo experimental do estudo da cicatrização e teste de drogas na pele, pelo fato dele já ter sido padronizado por muitas pesquisas $^{16,17,18}$.

Neste estudo foi escolhido o Wistar por ser de pequeno porte, de fácil aquisição e padronização no que diz respeito à idade, peso, sexo, alojamento, alimentação, cuidados de limpeza e manipulação experimental. Ele ainda apresenta muito boa resistência à manipulação e agressão cirúrgica, às infecções e podem ser utilizados em amostras significativas, para constituição subgrupal, tendo possibilidade de anestesia por via inalatória, intraperitonial ou intravenosa, conforme o experimento.

A pele de rato apresenta diferença importante em relação à humana que é a ausência de um limite definido entre derme papilar e derme reticular. McFarlane et al. ${ }^{19}$ referem que, apesar dos achados histológicos diferentes da pele humana (a derme do rato é mais espessa e não apresenta tecido gorduroso subcutâneo nem tela muscular subcutânea), os vasos sanguíneos responsáveis pela irrigação cutânea são subdérmicos em ambos e apresentam as mesmas alterações de perfusão de macro e microvascularização.

No primeiro período de observação, ou seja no $7^{\circ}$ dia de pós-operatório, houve formação de crosta mais exuberante no grupo Jatropha do que no controle. A partir do $14^{\circ}$ até o $21^{\circ}$ dias houve evolução igual na reparação tecidual do ferimento cutâneo.

A área da ferida evoluiu com diminuição gradativa, não havendo diferença significativa entre os grupos controle e Jatropha. A avaliação da área da ferida com a planimetria digital, também não mostrou diferença significativa.

O processo de reparação tecidual apresenta várias fases com características próprias que se desenvolvem concomitantemente ${ }^{20,21}$. Após a retirada do fragmento de pele ocorre a formação de uma solução de continuidade que é preenchida inicialmente por fibrina, coágulo e exsudato inflamatório, formando a crosta que recobre a ferida ${ }^{17,20}$. A espessura da crosta no grupo Jatropha foi significamente maior quando comparado ao grupo controle no $7^{\circ}$ dia de pós-operatório.

A fase subseqüente da reparação é a inflamação, com a presença de exsudato inflamatório, vasodilatação, aumento da permeabilidade vascular, extravasamento de plasma, hemácias, leucócito, principalmente neutrófilos e monócitos seguida da presença de macrófagos ${ }^{20}$. O processo inflamatório foi encontrado neste estudo em ambos os grupos, não havendo diferença significativa entre os grupos no $7^{\circ}$, $14^{\circ}$ e $21^{\circ}$ dias.

$\mathrm{Na}$ fase de fibroplasia que se inicia cerca de 48 horas após a lesão, surgem os fibroblastos que se multiplicam e produzem componentes como a substância fundamental e o colágeno. Observa-se também, nesta fase intensa proliferação endotelial. Estes formam o tecido de granulação ${ }^{22}$. No $7^{\circ}$ dia o tecido de granulação foi encontrado em ambos os grupos estudados, sendo que no grupo Jatropha mostrou aumento de proliferação fibroblástica. No $14^{\circ}$ dia o tecido de granulação estava mais rico em fibroblastos, porém sem diferença significativa entre o grupo controle e o Jatropha. No $21^{\circ}$ dia não houve resultado significativo em relação à proliferação fibroblástica.

Em 1972, Alvares ${ }^{16}$ observou fibras colágenas dispostas paralelamente à superfície da lesão em torno do $14^{\circ}$ dia de evolução, coincidindo com a epitelização da lesão. Encontrou-se aqui situação semelhante; porém, no grupo Jatropha isto já ocorria parcialmente aos sete dias de pós-operatório, indicando processo de reparação mais adiantado neste grupo. Modolin et al. ${ }^{22}$ relatam que uma das características desta última fase do processo de reparação tecidual é a regressão endotelial. Observou-se fenômenos semelhantes neste estudo, tanto no grupo controle como no grupo Jatropha sem diferença significativa entre os grupos. Nesta fase ocorre a epitelização da lesão que é controlada por um complexo glico-protéico denominado chalona e que estimula a atividade mitótica epitelial ${ }^{22}$. Nas observações deste estudo, não encontrou-se diferenças entre os epitélios das lesões do grupo controle e das do Jatropha no $14^{\circ}$ e $21^{\circ}$ dias de observação. Aos 21 dias de pós-operatório, tanto o grupo controle como o grupo Jatropha apresentavam as lesões totalmente epitelizadas.

\section{Conclusão}

A avaliação do uso do extrato bruto de., em feridas cutâneas abertas de ratos foi semelhante ao controle no aspecto macroscópico e na análise da planigrafia digital, mostrando contudo melhora comparativa na cicatrização no grupo Jatropha no aspecto microscópico.

\section{Referências}

1. Lima DR. Medicamentos: passado, presente e futuro. In: Lima DR, editor. Manual de Farmacologia Clínica, Terapêutica e Toxicologia. Rio de Janeiro: Guanabara Koogan; 1994. p. 13. 
2. Adewernmi CO, Adesogan EK. Toxicology of some nigerian plants and Schistosomiasis control - I. The effect of molluscicides ou Molluscan heart. Fitoterapia. 1986;(58):354 -8.

3. Biondo-Simões MLP, Adur RC, Marques LO, Lima EJB, Rosario MAK. Açúcar e ácido acexâmico na cicatrização de feridas cutâneas em ratos. Acta Cir Bras. 1993;(8):834.

4. Brito NMB. Aspectos morfológicos e morfométricos da cicatrização de feridas cutâneas abertas em ratos tratados com óleo de copaíba. [Dissertação-Mestrado]. São Paulo:Universidade Federal de São Paulo; 1996.

5. Eurides D. Morfologia e morfometria da reparação tecidual de feridas cutâneas de camundongos tratadas com solução de barbatimão (Stryphynodendron barbatiman martius). Rev Fac Zootec Vet Agro Uruguaiana. 1995/1996; 2/3:37-42.

6. Marchini FB, Martins DMFS, Teves DC, Simões MJ. Efeito do óleo de rosa mosqueta na cicatrização de feridas abertas. Rev Paul Med. 1988;106:356.

7. Mesquita LEA. Estudo morfológico e morfométrico da cicatrização de feridas cutâneas abertas em ratos albinos com e sem tratamento com insulina. [Tese-Doutorado]. São Paulo: Universidade Federal de São Paulo, Escola Paulista de Medicina;1997.

8. Miranda LTGS. Uso da tintura de arnica em feridas cutâneas abertas em ratos. [Dissertação - Mestrado]. São Paulo:Universidade Federal de São Paulo, Escola Paulista de Medicina; 2001.

9. Abreu IC. Estudo do mecanismo vascular do extrato etanólico de Jatropha gossypiifolia L. (pião roxo) em artéria mesenteríca de ratos. [Monografia-Graduação]. São Luis (MA): Universidade Federal do Maranhão, Centro de Ciências da Saúde; 2002.

10. Abreu TRA. Estudo farmacológico da Jatropha gossypiifolia L. [Monografia-Graduação]. São Luís: Universidade Federal do Maranhão,Centro de Ciências da Saúde; 1992.

11. Corrêa MP. Dicionário das plantas úteis do Brasil e das exóticas cultivadas. Rio de Janeiro:Instituto Brasileiro de Desenvolimento Florestal, 1984.
12. França LG. Estudo fitoquímico preliminar da Jatropha gossypiifolia L. [Monografia- Graduação]. São Luis (MA): Universidade Federal do Maranhão, Centro Ciências da Saúde; 1992.

13. Emperaire L. Oréades. 1982;(8):61-71.

14. Barros MAG. O uso de sementes de Jatropha gossypyfolia L. Oréades. 1982;(8):140-51.

15. Amorozo MC, Gély A. Bol Mus Par. Emílio Goeldi: série Botânica. 1988; 4(1):47-131.

16. Alvares S. Contribuição para o estudo histométrico e histoquímico do processo de reparação de lesões obtidas experimentalmente na pele de ratos albinos. [Tese-Doutorado]. São Paulo: Universidade de São Paulo, Faculdade de Odontologia;1972.

17. Marchini FB. Estudo Morfológico e morfonético da Cicatrização de Feridas cutâneas abertas em ratos albinos com e sem tratamento com óleo de Rosa Mosqueta. [Dissertação - Mestrado]. São Paulo: Universidade Federal de São Paulo, Escola Paulista de Medicina;1994.

18. Masini E, Calamo MA. Uma forma de tratamento de lesões cutâneas com papaína e sacarose. Rev Bras Clin Terap. 1986;(15): 245-8.

19. McFarlane RM, Deyoung G, Henry RA. The desing of a pedide flap in the rat to study necrosis and its prevention. Plast Reconstr Surg. 1965;(35):177-82.

20. Bevilacqua RG, Modolin MLA, Almeida CG, Chapchap P. Cicatrização. In: Goldenberg S, Bevilacqua RG. Bases da Cirurgia. São Paulo: EPM/ Springer; 1981. P. 99116.

21. Czeczko NG. Estudo experimental do envolvimento de uma anastomose esofágica cervical por um retalho livre e autógeno peritonioaponeurótico. Trabalho experimental em cães. [Dissertação - Mestrado].Curitiba: Universidade Federal do Paraná, Setor de Ciências de Saúde; 1989.

22. Modolin M, Bevilacqua RG. Cicatrização das feridas. Síntese das aquisições recentes. Rev Bras Clin Terap. 1985;(14): 208-13.

\section{Correspondência:}

Rua Perpétuas, Quadra 9, Casa 4

Renasença II - São Luiz - MA

CEP: 60075-620
Conflito de interesses: nenhum Fonte de financiamento: Capes

Recebimento: $18 / 02 / 2005$

Revisão: 05/06/2005

Aprovação: 11/06/2006

\section{Como citar este artigo:}

Santos MFS, Czeczko NG, Nassif PAN, Ribas-Filho JM, Alencar BLF, Malafaia O, Ribas CAPM, Trautwein VM, Henriques GS, Maia JMA, Bittencourt RCA. Avaliação do uso do extrato bruto de Jatropha gossypiifolia L. na cicatrização de feridas cutâneas em ratos. Acta Cir Bras. [periódico na internet] 2006;21 Supl 3:2-7. Disponível em URL: http://www. scielo.br/acb

*Figuras coloridas disponíveis em www.scielo.br/acb 